Este trabalho destaca a importância da funça paterna no registro do psiquismo humano $\mathrm{c}$ as possibilidades decorrentes da mesma para o processo de simbolização.

Como se inscreve a sim. bolizaçĩo no psiquismo humano? Qual a importancia da função paterna para esse processo? Estas são questões postas em discussão, desenvolvendo uma abordagem que cvolui desde a infância. O texto traz uma reflexio sobre as estruturas clínicas destacando a função do falo, a posição do sujeito no Complexo de Édipo e as implicaçóes de sua transposição.

Também é analisado o processo de simbolização nas personalidades que vivenciaram o tracasso da função paterna e suas diferentes formas de manifestação, quais sejam as estruturas de personalidade neurótica ou psicótica.

Funçāo paterna; simbolização; psiquismo humano; cstruturas clínicas; Complexo de Edipo; falo.

THE FALL OF PATERNAL FUNCTION AND THE SYMBOLIZATION DIALETICS

This text stresses how important is paternal tunc. tion in humatn psychism. and what ate the possible outcomes of it in the sym. bolization process. How does the symbolization process inscribe in human psychism? How important is paternal function for that process?

These are the questions aroused in a developmental approach to childhood. There are the clinical structures, the phallus function, the positions in the Aedi. pus Complex and the impli. cations of its mouvement.

The process of symboli. zation is also analysed through the experience, of people whose foiling of the paternal function manitested itself in neurothic or psycothic person.lity structures. Paternal function; symbolization; human psychism; clinical structures; Aedipus Complex; phallus.

\section{DECLÍNIO DA FUNÇÃO PATERNA E DIALÉTICA DA SIMBOLIZAÇÃO}

\author{
Maria Nestrovsky Folberg \\ Noeli Reck Maggi
}

criança ao nascer, em virtude de seu desamparo e da sua absoluta dependência de outro, está submetida a este, que assegura sua sobrevivência e a sua entrada no mundo nomeado pela linguagem. Para que o sujeito se constitua e ingresse na cultura é necessário que um Outro ocupe esse lugar, "emprestando-lhe" seu olhar e sua voz, escutando o choro e transformando-o em chamada, mapeando o corpo com o toque e intermediando-o com o mundo. Geralmente, quem ocupa esse lugar é a mãe, e a opção que a criança faz pelos modos de resposta, ou por um desses lugares, vai depender do significante "falta" e, portanto, da sua relação com o desejo.

Meira (1996, p. 90), tecendo um comentário sobre as idéias de Lacan, diz que, "no campo da linguagem, não se trata de um processo objetivo com relação ao ser humano, não se trata de uma simples maturação. Não nega a existência da maturação do organismo, mas inclui um sujeito que dá

- Doutora em Educação, professora dos Cursos de PósGraduação em Educação da FACED-UFRGS

- Doutoranda em Educação, PPG/FACED-UFRGS. 
sentido ao ocorrido". Além disso, ela continua, "o fator tempo não deve ser, porém, desconsiderado. É importante diferenciar o tempo métrico, que aparece na cronologia, e o tempo lógico", onde se pode lembrar Freud, que, ao considerar os estágios oral, anal e fálico do desenvolvimento da libido, destacou não apenas o elemento cronológico dos primeiros anos, mas também, e principalmente, os núcleos de fixaçāo reeditados na vida posterior em função do caráter econômico das energias investidas. Assim, vemos que cada núcleo de energia fixada em determinado momento do desenvolvimento é "revisitado" em função das reedições determinadas por um desejo, desejo este que demanda ressignificar-se.

Sabemos que as manifestações do psiquismo abrangem recordações encobridoras que anunciam e denunciam a trama, o desejo do sujeito e a forma como expressa o seu gozo. A função materna não só satisfaz as necessidades, mas também as nomeia. Ela "dá" significado de fome, de frio ou de dor para o choro; é um caminho para chegar ao simbólico que se está estruturando.

A percepção que a criança tem do próprio corpo como uma unidade é uma experiência que evolui desde percepções vagas, mas que envolve um estado de auto-erotismo, para em seguida marcar a passagem ao narcisismo primário. A mãe, como "elemento-função", faz essa passagem pela linguagem, transmissora de códigos e de significações oferecidas à criança. Ela é o código por excelência. A imagem que a criança constrói de si mesma é decorrente do espelho-mãe, oferecido pelo olhar, pelos gestos, pelo toque e por todas as traduçōes feitas a partir das demandas manifestadas pelo bebê e significadas pelo adulto-mãe que está aí.

Em relação ao pai, trata-se menos da presença ou ausência de um pai real, mas de um lugar no discurso materno e de sua significação para a criança. Remete à "função paterna", o representante da lei, que interdita o acesso onipotente da criança à mãe. A análise dos diferentes significados que a função paterna exerce permite designá-la desde o lugar de um pai biológico até o lugar do representante simbólico da lei, dos valores e dos ideais de vida estabelecidos pelo sujeito.

Não se trata de uma passagem linear, em que o pai "tutor" $e$ "castrador" é substituído por outra dimensão de pai. Trata-se de uma passagem através de movimentos contraditórios em que a dialética entre a morte e a recriação está continuamente presente. A figura do pai a partir da psicanálise é articulada pelo investimento afetivo destinado a um terceiro, período em que a criança está saindo do seu estado de onipotência.

O lugar ocupado pela criança é determinado a partir da subjetividade dos pais. O pai tem um determinado registro no discur- 
so materno em função do Édipo, vivenciado no percurso do seu desenvolvimento. A entrada do pai é função que interdita a energia pulsional do sujeito, necessária para que o narcisismo ceda lugar à castração simbólica.

É a partir da transposição desse pai "castrador" que o sujeito vai expressar a sua potencialidade e todo o conteúdo já nomeado e emprestado pela função materna desde os momentos iniciais. Falar em "declínio da função paterna" significa situar os representantes subjetivos da constelação familiar, incluindo pai, mãe e filho, com suas características físicas, da ordem de nascimento na família e da rede significante desses múltiplos personagens.

\section{FUNÇÃO DO FALO E POSIÇÃO DO SUJEITO NO COMPLEXO DE ÉDIPO}

Diz Meira (1996, p. 89): “A criança acredita, inicialmente, que esse Outro não tem falhas, que tudo sabe e que a tudo pode responder. A certa altura, a criança descobre que esse Outro não é pleno, que lhe falta algo, o que a introduz no registro do desejo. A criança tenta se localizar como sujeito, dirigindo ao Outro uma pergunta: o que o Outro quer de mim? As estruturas clínicas podem, pois, ser situadas como modos de resposta à questão do desejo do Outro".

Antes de nascer, o ser humano já tem um lugar que o espera. Esse meio cultural ao qual ele pertence está inscrito com valores, ritos, leis e possibilidades tanto de reconhecimento como de alienação. O lugar reservado ao ser que está chegando é constituído de fantasias, lendas, desejos, imaginação que fazem parte da herança psíquica dos pais. "Encontrar o mundo" é também poder reconhecê-lo tanto como familiar quanto como estranho; é poder transformá-lo a partir das diferenças que lhe são possibilitadas na relação com os objetos primários de amor. Seu psiquismo se constitui utilizando os mecanismos que possibilitam dar sentido à sua existência, seja para viver na neurose ou na psicose.

Os cuidados maternos fortalecem sua capacidade para viver e se desenvolver, mesmo não sendo capaz de discriminar no ambiente o que lhe causa prazer ou frustração, ou mesmo de se sentir responsável pelo que lhe ocorre. É nessa perspectiva teórica que Winnicott (1962) realça a importância do ambiente facilitador para o desenvolvimento de um ego sadio a fim de, mais tarde, a criança poder suportar a luta pela independência, ainda que relativa, rumo ao mundo da criação e simbolização. 
Para Freud (1917), as séries complementares dão origem à estruturação psíquica, compreendendo que o fator constitucional, o das primeiras experiências, e as situações a que o sujeito é submetido no quotidiano estão intimamente relacionados. Em virtude de seu hilflosigkeit, seu desamparo inicial, sua dependência, o ser humano está submetido a um outro.

No início, este outro tudo sabe, não tem falhas e tem todas as respostas para as necessidades: ocupa um lugar de completude. A criança acredita que a mãe encarna esse lugar. Mais tarde, ela virá a descobrir que esse outro não é pleno nem onipresente, mas barrado pela falta, uma falta constituinte. A partir dessa constatação, podem ocorrer diferentes posições da estrutura psíquica perante o outro e o desejo do Outro. Para Lacan (1964), é a partir desse espaço da falta que se origina o desejo. O falo ocupa o lugar vazio, o lugar da incompletude, o lugar para onde se dirige o olhar da mãe, uma vez que ela também sente-se incompleta.

Mas o que é o falo? Segundo Lacan (1964), é um significante, uma palavra ou um objeto que tornaria o sujeito completo. $\mathrm{O}$ falo marca como símbolo a substituição do objeto; assim, o espaço da falta estará lá onde se originam o desejo, o pensamento e a criatividade.

Os elementos que suportam essa construção psíquica envolvem a relação do sujeito com a falta, com o falo, com a castração, o que quer dizer também com a lei. O processo de simbolização finca suas raízes lá onde o objeto não é todo subjetivo e onde o sujeito não é todo objetivo. A constituição psíquica que origina a simbolização está ancorada no Édipo onde o sujeito é submetido à castração, embora cada um se situe com um modo de resposta, a ocupar diferentes lugares frente ao desejo do outro. Desde a infância existe o indicativo da organização de uma estrutura e mais tarde, na adolescência, a estrutura do Édipo é reeditada com possibilidades de mudança, dependendo do tipo de recordação encobridora. Pensar no processo de simbolização é retomar os elementos básicos estabelecidos nas primeiras relações do bebê com o entorno, transitando pelo desejo, pela demanda, pela castração, pelos fenômenos transicionais, pelo falo, pela demanda.

São estruturas clínicas que indicam o modo de relação estabelecido pelo sujeito no circuito da falta e, portanto, do desejo. O neurótico, porque mantém afastadas da consciência representações censuradas e perigosas, é capaz de expressá-las pelo processo secundário, ou seja, através do pensamento e da linguagem. O psicótico, por sua vez, ao deparar com a falta do Outro, de um outro diferente do Outro, coloca-se como aquele que vai completar a falta, ou seja, coloca-se como o falo e rejeita a castração. Já o perverso 
recusa a castração do Outro e a difícil realidade da falta pela diferença dos sexos, atribuindo um falo à mãe. Se os dois últimos têm dificuldade de simbolizar, o mesmo não ocorre com o neurótico, cujas marcas do Édipo possibilitam a castração e o recalcamento.

Enquanto o neurótico confirma a hipótese de que o superego é o herdeiro do Complexo de Édipo, o psicótico não entra na dialética edipiana porque rejeita a realidade, e o perverso recusa a castração mantendo uma relação particular com a lei, manifestando um gosto especial em transgredir, desafiar e gozar. Parece até que aceita em parte a lei para gozar.

Para ilustrar, eis a dinâmica de funcionamento da estrutura clínica da histérica analisada por Lacan (1957-58). A partir dos primeiros estudos de Freud, revela-se a incansável busca de um grande Outro "completo", "dono e senhor de seu desejo", o que na verdade a faz ficar sem desejo. Está sempre procurando agradar ao Outro na tentativa de estabelecer o brilho fálico enfraquecido. A histérica denuncia a impotência fálica, em nome de um falo mais potente, mas ela demanda mais que o falo. Falar da histérica como de uma outra neurose, da psicose ou da perversão é pensar em modos diferentes de lidar com a falta. Diante da falta, coloca-se "algo", aquilo que define a forma de ser do sujeito e o seu modo de gozar.

É importante destacar a interpretação de Lacan (1964) a respeito da função do falo como organizador universal das pulsões. A posição 
do sujeito frente aos significantes culturais será decorrente da sua relação com o falo bem como da transposição do Édipo, elemento fundante do psiquismo. Portanto, o recalcamento é básico e estruturante na constituição do (\$) humano e é instalado a partir da metáfora paterna, momento em que o desejo da mãe é intermediado pela "lei" ou por um operador da cultura que tenha valor de representação.

$\mathrm{Em}$ As formações do inconsciente, Lacan (1957-58) descreve os três tempos do Édipo para analisar como se organizam as estruturas clínicas e onde se situam o neurótico, o psicótico e o perverso. No primeiro tempo do Édipo a criança está "assujeitada” à mãe por ainda se encontrar numa relação especular e identificada com o objeto do seu desejo. No segundo tempo, entra o pai, privando a mãe do objeto fálico e por conseqüencia privando a criança do objeto do seu desejo. Esta é uma etapa importante porque possibilita à criança identificar-se com a lei que the garante ter acesso à dialética do ter. O pai real que aparece como o representante da lei passa a ser investido de uma significação nova pela criança desde o momento em que ele ocupa o lugar de ser o objeto de desejo da mãe. No terceiro tempo, o pai intervém não como aquele que é o falo, mas como "aquele que detém o falo", reassegurando que o falo continua sendo objeto desejado pela mãe e do qual ela não foi privada. Esse momento assinala a instalação do Ideal de Eu; lugar de passagem do registro do ser ao ter; tempo em que a criança tem acesso a um pai permissivo e doador.

A identificação com aquele que tem o falo é a prova manifesta do recalque originário e da instalação da metáfora paterna, uma vez que a criança fornece indícios de não ter fugido da castração, mas de encontrar "saídas" para a mesma através de mecanismos que fortalecem esse "ideal de eu".

É muito importante esse momento para a estrutura do sujeito na medida em que ele se percebe incompleto, mas com possibilidades de buscar o que the falta, estabelecendo objetivos e perspectivas futuras em termos de um "ideal" a ser perseguido. Isso representa buscar o que the falta, estabelecer objetivos e metas, pensar e criar, ou seja, sair do estado de onipotência e indiferenciação. Cada sujeito se define pelo seu modo de gozar; gozo que faz parte de uma estrutura e que se organiza a partir da infância e se define melhor a partir da adolescência.

\section{DECLÍNIO DA FUNÇÃO PATERNA E PROCESSO DE SIMBOLIZAÇÃO}

A função simbólica parece acompanhar, sempre, todos os processos vitais humanos que estão situados além da condição material e temporal. É uma elaboração que ocorre no campo do psiquismo, vivida pelo sujeito em todas as relações com ele mesmo e com os outros. "A função simbólica implica, pois, a noção de 
similitude reconhecida, portanto a noção de sensação autônoma; implica a noção do "já vivido", isto é, a noção do espaço e do próprio corpo neste espaço...”, diz Françoise Dolto (1988, p.102).

As primeiras relações do sujeito com a mãe, antes mesmo do nascimento, já estão plenas de simbolismo e para que haja diferenciação desses dois elementos é necessário que um terceiro opere a instalação de um corte ou de um limite. Desenrola-se o estádio do espelho e instala-se o eu. Na psicose infantil, a mãe introduz seu bebê no estádio do espelho com júbilo; esse processo de libidinização não oportuniza mais a sua saída. O ordenamento necessário para orientar-se no mundo humano e ter desejo próprio é possibilitado à criança pelo processo de simbolização. Ao articular o pensar com a formação de símbolos, Winnicott reconhece a estreita relação entre ambos. Para ele, o pensar começa como uma maneira pessoal que o bebê tem para lidar com o fracasso de adaptação da mãe. A patologia do processo de simbolização aparece quando há uma adaptação forçada, ou seja, um fracasso da adaptação em função de uma atitude inadequada da mãe. Decorrente dessa relação, o "pensar" não envolve criatividade e imaginação, mas torna-se um sonho.

Pela introjeção de elementos do objeto externo, que passam a fazer parte do próprio sujeito num processo de intra e intersubjetividade de forma inseparável, organiza-se um espaço potencial onde se originam a criatividade, o espaço do brincar e da formação de símbolos. É nesse espaço que o sujeito transita entre "ser" e "ter", entre o "eu" e o "não eu"; espaço de diferenciação, de formação do ideal do eu e início da simbolização.

Diz Lacan (1957-58), que a função do ideal do eu não é encontrada em dicionários e é mais bem compreendida na relação intersubjetiva, desempenhando uma função tipificadora do desejo do sujeito. Isso significa uma imagem do pai tutor esmaecida pela renúncia e pelo luto, retomada pelas continuadas expressões simbólicas do sujeito. A recriação da paternidade é um processo dialético que acompanha toda a existência humana e tem sua inscrição precocemente estabelecida desde as relações iniciadas entre a mãe e o bebê.

Ao ser capaz de renunciar ao poder, o sujeito está identificando-se a um pai mortal e reconhecendo-o: essa é a condição da neurose. $\mathrm{O}$ fracasso da função paterna não possibilita uma diferença, um reconhecimento de incompletude e, nessas condições, o sujeito encontrará dificuldades para buscar e criar o que lhe falta, pois "nada lhe falta". Há uma marca de onipotência e narcisismo que inviabiliza as trocas e os projetos que constituem os ideais de existência futura. O neurótico é capaz de simbolização por meio 
do processo secundário, ou seja, do pensamento, da criação e da busca de uma vida cultural ativa. Já o processo de simbolização do psicótico está ancorado pela alucinação e pelo pensamento mágico. Se não houve a castração simbólica, não existe falta e, portanto, não há o que criar.

Não basta que a criança assimile a lei como repressão dos impulsos, é preciso que a transforme em ação, o que em outras palavras chamamos de sublimação. Assim, nesse processo dialético em que há uma destruição que se mostra estruturante, essa pulsão investida nos objetos tem seu destino e sua ordem diferentes. Há a energia para o sujeito utilizar na ação no sentido do seu desenvolvimento, de sua criatividade e transformação. É na medida em que o processo evolutivo vai ocorrendo que a simbolização como mecanismo de ordem superior vai assumindo lugar. Na simultaneidade destruição e crescimento, há uma aufhebung hegeliana ${ }^{1}$ no reconhecimento através da identificação. $\mathrm{Na}$ medida em que a função paterna oportuniza o espaço da falta, também abre espaço para esse olhar de incompletude e de busca por um ideal. Por isso, a função paterna é uma designação ampliada do elo de parentesco desde que a "morte do pai" e o seu reconhecimento são parte da história do sujeito. A recriação da paternidade pelo sujeito envolve um processo dialético que acompanha toda a existência humana.

O que inicialmente é limitado à relação de parentesco ressurge depois através de diferentes designações possibilitadas pela relação inter-humana; a renúncia à imagem de um pai tutor rompe com a condição narcísica de um sujeito indiferenciado, liberando-o para a condição de sujeito de seu desejo e capaz de vivenciar o luto e a recriação como condição humana necessária para a criação e atravessado pela possibilidade da simbolização.

\section{REFERENCIAS BIBLIOGRÁFICAS}

Dolto, F. (1988). Dificuldade de viver. Porto Alegre, RS: Artes Médicas.

Freud, S. (1917). Conferência XX111 - Os caminhos da formação dos sintomas. In Edição standard brasileira das obras completas de Sigmund Freud. Rio de Janeiro, RJ: Imago, 1976.

Lacan, J. (1957-58). O seminário: as formaçóes do inconsciente - Livro 5. Rio de Janeiro, RJ: Jorge Zahar, 1999.

(1964). O seminário: os quatro conceitos fundamentais da psicanálise Livro 11. Rio de Janeiro,RJ: Zahar, 1979. Meira, Y. M. (1996). As estruturas clínicas e a criançal. Belo Horizonte, MG: A.S. Passos Editora.

Winnicott, D. W. (1962). O ambiente e os processos de maturaçĩo. Porto Alegre, RS: Artes Médicas, 1983.

NOTA

1 A aufhebung hegeliana que reconhecemos neste processo dialético vem resgatar a possibilidade de crescimento a partir da manutenção da pulsão, ou seja, há uma reformulação, um crescimento sem perda do existente até aqui (N. do T.).

Recebido em fevereiro/2002. 